\title{
A Scoping Review of Professional Identity Formation in Undergraduate Medical Education
}

\author{
Shiva Sarraf-Yazdi, MD, MEHP', Yao Neng Teo ${ }^{2,3}$, Ashley Ern Hui How ${ }^{3,4}$, Yao Hao Teo 2,3, \\ Sherill Goh', ${ }^{2,3}$, Cheryl Shumin Kow 2,3, Wei Yi Lam²,3, Ruth Si Man Wong, ${ }^{2,3}$, \\ Haziratul Zakirah Binte Ghazali3, Sarah-Kei Lauw',3, Javier Rui Ming Tan',3, \\ Ryan Bing Qian Lee $e^{2,3}$, Yun Ting Ong ${ }^{2,3,5}$, Natalie Pei Xin Chan ${ }^{2,3}$, \\ Clarissa Wei Shuen Cheong2,3, Nur Haidah Ahmad Kama2,3, \\ Alexia Sze Inn Lee, BSc (Psychological Science) ${ }^{6}$, Lorraine Hui En Tan²,3, \\ Annelissa Mien Chew Chin, MSc (Info \& Lit) ${ }^{7}$, Min Chiam, MSc (Medical Humanities) ${ }^{6}$, \\ and Lalit Kumar Radha Krishna, MBChB, FRCP, FAMS, MA (Medical Education), MA \\ (Medical Ethics), PhD (Medical Ethics) ${ }^{7,2,3,5,6,8,9,10}$
}

\begin{abstract}
'Duke-NUS Medical School, Singapore, Singapore; ${ }^{2}$ Yong Loo Lin School of Medicine, National University of Singapore, Singapore, Singapore; ${ }^{3}$ Division of Supportive and Palliative Care, National Cancer Centre Singapore, Singapore, Singapore; " Lee Kong Chian School of Medicine, Nanyang Technological University, Singapore, Singapore; ${ }^{5}$ Singapore Health Services, Singapore, Singapore; ${ }^{6}$ Division of Cancer Education, National Cancer Centre Singapore, Singapore, Singapore; ${ }^{7}$ Medical Library, National University of Singapore Libraries, Singapore, Singapore; ${ }^{8}$ Palliative Care Institute Liverpool, Academic Palliative \& End of Life Care Centre, University of Liverpool, United Kingdom, Cancer Research Centre, University of Liverpool, Liverpool, UK; ${ }^{9}$ Centre of Biomedical Ethics, National University of Singapore, Singapore, Singapore; ${ }^{10}$ PalC, The Palliative Care Centre for Excellence in Research and Education, Singapore, Singapore.
\end{abstract}

BACKGROUND: Professional identity formation (PIF) in medical students is a multifactorial phenomenon, shaped by ways that clinical and non-clinical experiences, expectations and environmental factors merge with individual values, beliefs and obligations. The relationship between students' evolving professional identity and self-identity or personhood remains ill-defined, making it challenging for medical schools to support PIF systematically and strategically. Primarily, to capture prevailing literature on PIF in medical school education, and secondarily, to ascertain how PIF influences on medical students may be viewed through the lens of the ring theory of personhood (RToP) and to identify ways that medical schools support PIF.

METHODS: A systematic scoping review was conducted using the systematic evidence-based approach. Articles published between 1 January 2000 and 1 July 2020 related to PIF in medical students were searched using PubMed, Embase, PsycINFO, ERIC and Scopus. Articles of all study designs (quantitative and qualitative), published or translated into English, were included. Concurrent thematic and directed content analyses were used to evaluate the data.

RESULTS: A total of 10443 abstracts were identified, 272 full-text articles evaluated, and 76 articles included. Thematic and directed content analyses revealed similar themes and categories as follows: characteristics of PIF in relation to professionalism, role of socialization in PIF, PIF enablers and barriers, and medical school approaches to supporting PIF.

DISCUSSION: PIF involves iterative construction, deconstruction and inculcation of professional beliefs, values and behaviours into a pre-existent identity. Through the lens of RToP, factors were elucidated that promote or hinder students' identity development on individual, relational or societal levels. If inadequately or inappropriately supported, enabling factors become barriers to PIF. Medical schools employ an all-encompassing approach to support PIF, illuminating the need for distinct and deliberate longitudinal monitoring and mentoring to foster students' balanced integration of personal and professional identities over time.

KEY WORDS: professional identity; professional identity formation; PIF; personhood; ring theory of personhood.

$\begin{array}{ll}\text { Abbreviations } \\ \text { PIF } & \begin{array}{l}\text { professional identity formation } \\ \text { ring theory of personhood }\end{array} \\ \text { RToP } & \text { systematic evidence-based approach } \\ \text { SEBA } & \text { systematic scoping review } \\ \text { SSR } & \text { Yong Loo Lin School of Medicine } \\ \text { YLLSoM } & \text { National University of Singapore } \\ \text { NUS } & \text { National Cancer Centre Singapore } \\ \text { NCCS } & \begin{array}{l}\text { Preferred Reporting Items for Systematic Reviews and } \\ \text { PRISMA }\end{array} \\ \text { PICOS } & \begin{array}{l}\text { Meta-Analyses } \\ \text { population, intervention, comparison, outcome, study } \\ \text { design }\end{array} \\ \text { MERSQI } & \begin{array}{l}\text { Medical Education Research Study Quality Instrument } \\ \text { Consolidated Criteria for Reporting Qualitative }\end{array} \\ \text { COREQ } & \begin{array}{l}\text { Studies } \\ \text { Best Evidence Medical Education }\end{array} \\ \text { BEME } & \text { Structured approach to the Reporting In healthcare } \\ \text { STORIES } & \text { education of Evidence Synthesis }\end{array}$

J Gen Intern Med 36(11):3511-21

DOI: $10.1007 / \mathrm{s} 11606-021-07024-9$

(c) The Author(s) 2021 


\section{INTRODUCTION}

Professional identity in medicine refers to one's "interpretation of what being a good doctor means and the manner in which he or she should behave" ${ }^{1}$. Holden et al. ${ }^{2}$ describe professional identity formation (PIF) "as the foundational process one experiences during the transformation from lay person to physician". Growing data suggest that PIF is heavily influenced by how medical students evaluate their professional roles and responsibilities in light of fluid circumstances and clinical experiences. This developmental process is shaped by sociocultural, familial, academic, moral, religious and genderbased roles, values, beliefs and obligations ${ }^{3-6}$. The complexity herein underlines the challenge that medical schools face in viewing and reviewing their approaches to fostering PIF ${ }^{7-10}$.

Identity is a manifestation of qualities, conditions, beliefs, values and ideals that humans possess and regard with importance. While core components remain foundational and enduring, identity exists in a perpetual state of flux with elements taking on different forms and priorities. Moss et al. ${ }^{11}$ posit that professional identity "is the integration of the professional self and the personal self". This suggests a connection between PIF in medical school and the students' own concept of identity or personhood.

Personhood has been conceived in a plethora of ways. While Buron's ${ }^{12}$ levels of personhood considers individual, biological and sociological concepts, Dennett ${ }^{13}$ underscores the importance of communicative and cognitive faculties. A number of these concepts incorporate Lockean ${ }^{14}$ and Kantian's ${ }^{15}$ formulations that necessitate the presence of consciousness, rationality, self-awareness, intelligence, moral value, attainment of legal status ${ }^{16}$ and personal, enduring interests ${ }^{17-20}$. What these static frameworks do not consider is the dynamic influence of one's changing beliefs, attitudes and perceptions on decision-making ${ }^{21-23}$. Similarly, existing concepts of PIF in medical students do not holistically acknowledge the evolving person behind the budding professional.

To explore these gaps, we adopted Krishna and Alsuwaigh's ring theory of personhood (RToP) ${ }^{24,25}$, which characterizes personhood as four interconnected rings - the Innate, Individual, Relational and Societal (Figure 1). This framework considers the evolving nature of personhood and various sources of influence that inform one's self-concept of identity, i.e. what makes us who we are ${ }^{26,27}$. The Innate Ring represents qualities that remain steadfast such as an individual's genetic makeup and the family, society, culture, religion, race and gender into which an individual is born. Though some features may change, these impact an individual's development and often form the basis of who they are as a person. The Individual Ring represents one's conscious function and ability to communicate and display emotions. Beliefs and values within this ring are informed by its specific contents. A religious individual, for example, holds beliefs, values and principles associated with their religious stance. The more

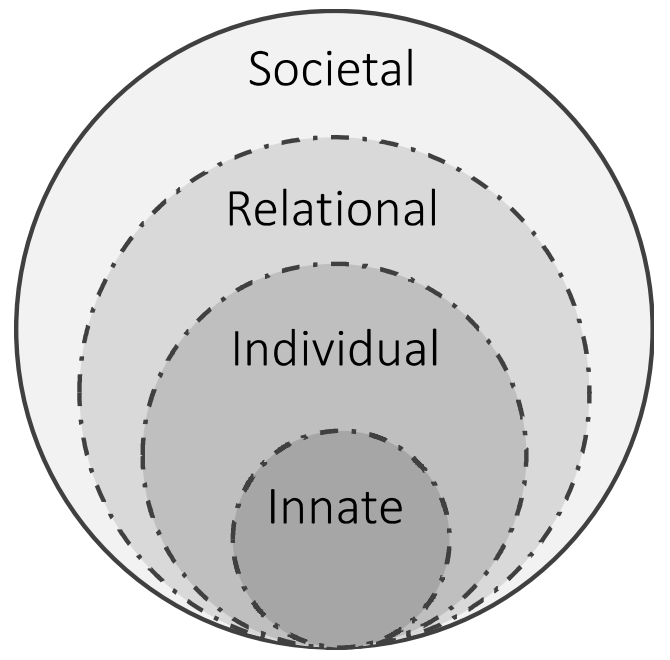

Figure 1 The four rings of personhood in RToP

strongly the individual upholds these, the more it impacts their thoughts, decisions and actions. This highlights the entwined nature of various aspects of personhood and the role of the Individual Ring in shaping identity. The Relational Ring depicts the close personal ties that one shares with those deemed important. The Societal Ring houses more distant relationships as well as social expectations, cultural norms, professional standards and religious obligations placed upon the individual. These include codes of conduct and practice expected of the person by virtue of their membership within society.

One's self-concept of identity can thus influence, exist as a part of, and encapsulate an evolving professional identity. To explore this concept in the medical school context, we aimed to capture the various elements of PIF through a scoping review, and used the RToP as an organizing framework to explore how fluid circumstances related to professional identity development may affect a medical student's personhood.

\section{METHODS}

We used a systematic scoping review (SSR) to map available data on PIF in prevailing undergraduate medical education literature and to identify information related to key characteristics of PIF within this context ${ }^{28,29}$. To overcome the absence of a consistent approach to conducting scoping reviews ${ }^{30}$, a 16-member research team applied Krishna's systematic evidence-based approach (SEBA) ${ }^{31-33}$. The six-stage structured process (Figure 2) provides a reproducible and transparent means of reviewing the search process, and the manner in which the data was accrued, analyzed and used to inform the conclusions drawn within the SSR.

SEBA's constructivist perspective allowed for capture of psychosocial, cultural and historical influences that underpin individual concepts of PIF, and its relativist lens enabled a holistic picture by considering various perspectives through data collected from quantitative, qualitative and knowledge synthesis articles. 


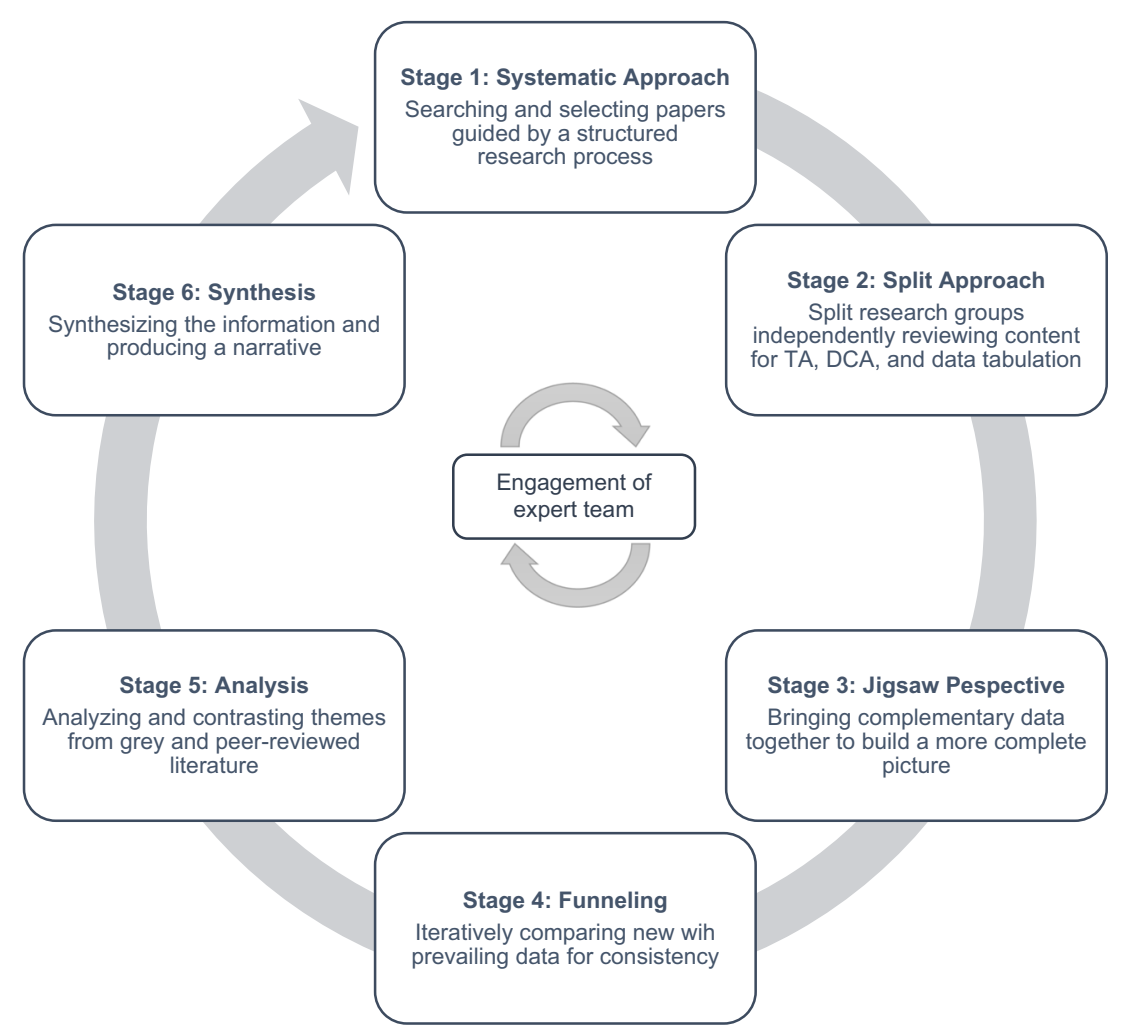

Figure 2 A schematic of the steps involved in systematic evidence-based approach (SEBA). Abbreviations: TA, thematic analysis; DCA, directed content analysis; BEME, Best Evidence Medical Education; STORIES, Structured approach to the Reporting In healthcare education of Evidence Synthesis

Each stage of SEBA additionally involved input from an expert team that guided the practical approach to the project, while independently reviewing and accounting for data collection, analysis and synthesis. The expert team comprised a medical librarian from the Yong Loo Lin School of Medicine (YLLSoM) at the National University of Singapore (NUS), and educational experts and clinicians from the National Cancer Centre Singapore (NCCS), the Palliative Care Institute Liverpool, YLLSoM and Duke-NUS Medical School.

\section{Stage 1: Systematic Approach}

A. Determining the background of review

The research and expert teams reviewed the overall objectives of the SSR, and determined the population, context and concept to be evaluated. This decision was guided by the preferred reporting items for systematic review and meta-analysis protocols (PRISMA-P) 2015 checklist $^{34,35}$ (see Appendix 1).

\section{B. Identifying research questions and Inclusion Criteria}

Teams agreed for the primary research question to be "what is known of PIF in medical school education?" To ascertain the wider impact of PIF on the self-concept of medical students, these secondary research questions were identified: "how may influences of PIF be viewed through the RTOP lens?" and "how do medical schools support PIF?"

A PICOS format framed the research process ${ }^{36,37}$ and may be found in Appendix 2. Guided by the expert team and prevailing descriptions of PIF, the research team developed a search strategy for PubMed, Embase, PsycINFO, ERIC and Scopus databases. Independent searches were carried out for articles published between 1 January 2000 and 1 July 2020 . The full PubMed search strategy may be found in Appendix 3. All research methodologies (quantitative and qualitative) in articles published or translated into English were included.

III. Selecting included articles

The sixteen members of the research team independently reviewed the identified titles and abstracts, created lists of articles to be included, discussed these online, and reached consensus using Sandelowski and Barroso's 38 "negotiated consensual validation" approach. Acknowledging limitations of the search terms, the members also performed reference snowballing. The PRISMA flow diagram can be found in Appendix 4.

\section{Assessing quality of articles}

Eight research team members individually appraised the quality of the quantitative and qualitative studies using the Medical Education Research Study Quality Instrument (MERSQI) ${ }^{39}$ and Consolidated Criteria for Reporting Qualitative Studies (COREQ) ${ }^{40}$. This allowed us to evaluate the methodology employed in the included articles, aid readers and reviewers in appraising the extent to which we reported the data, the weight we afforded the data in our analysis ${ }^{41}$ and assist decision-makers in understanding the transferability of the findings ${ }^{42}$. The 
analysis of 43 of 76 included articles amenable to quality appraisals may be found in Appendix 5.

\section{Stage 2: Split Approach}

To increase the reliability and transparency of the analysis, the Split Approach was adopted ${ }^{43,44}$. Seven members of the research team independently analyzed the data using Braun and Clarke's ${ }^{45}$ approach to thematic analysis. Concurrently, nine members of the research team employed Hsieh and Shannon's ${ }^{46}$ directed content analysis to independently analyze the data. This concurrent analysis aimed to reduce omission of new findings or negative reports and enable review of data from different perspectives. The reviewers within each sub-team achieved consensus on their analyses before comparing with the other two.

\section{A. Thematic analysis}

In the absence of rigorous definitions of PIF, seven members of the research team adopted Braun and Clarke's approach to identifying key themes across different learning settings and learner/instructor populations ${ }^{47,48}$. This allowed for analysis of data derived from quantitative, qualitative and mixed methodologies ${ }^{49,50}$. This sub-team independently reviewed the included articles, constructed codes from surface meaning of the text and collated these into a code book, which was used to code and analyze the rest of the articles in an iterative process. New codes were associated with prior codes and concepts ${ }^{51,52}$. An inductive approach allowed us to identify codes and themes from the raw data without using existing frameworks or preconceived notions as to how the data should be organized. The sub-team discussed their independent analyses in online and face-to-face meetings and used "negotiated consensual validation" to derive the final themes.

\section{B. Directed content analysis}

Nine members of the research team independently employed Hsieh and Shannon's approach to directed content analysis. This involved "identifying and operationalizing a priori coding categories" by classifying text of similar meaning into categories drawn from prevailing theories ${ }^{46}$. Four members first used deductive category application ${ }^{53}$ to extract codes and categories from Cruess et al.' $\mathrm{s}^{54}$ article, "A schematic representation of the professional identity formation and socialization of medical students and residents: A guide for medical educators".

Separately, to ensure adequate focus on the RToP domains, five members used Krishna and Alsuwaigh's ${ }^{24}$ article, "Understanding the fluid nature of personhood - the ring theory of personhood" to draw the categories to be used as part of Hsieh and Shannon's approach to directed content analysis. This was to evaluate the prevailing data through the lens of RToP and to answer the secondary research question on how PIF influences may be viewed through the lens of RToP. A code book was developed and individual findings were discussed through online and face-to-face meetings. Differences in codes were resolved until consensus was achieved on a final list of categories.

\section{Stage 3: Jigsaw Perspective}

The Jigsaw Perspective hinges on Moss and Haertel's ${ }^{55}$ suggestion that complementary qualitative data should be reviewed together to give "a richer, more nuanced understanding of a given phenomenon". It considers each finding as a piece of jigsaw that combined with appropriate or complementary pieces, portrays a more complete picture. The research team thus identified and combined significant overlaps and similarities between themes and categories to gather a holistic picture of available data on PIF and RToP.

\section{Stage 4: Funnelling}

Six members of the research team further summarized and tabulated the full-text articles included in the review according to Wong et al.' ${ }^{56}$ RAMESES publication standards and Popay et al.' ${ }^{57}$ guide to conducting narrative synthesis in systematic reviews. This was to verify that the jigsaw pieces appropriately reflected key insights from the prevailing data, ensuring that critical information was not lost.

To assist with this process, the team adopted Phases 3 to 6 of France et al.' $\mathrm{s}^{58}$ adaptation of Noblit and Hare's ${ }^{59}$ seven phases of meta-ethnography to study the included articles ${ }^{60}$. In line with Phase 3, the study aim, key findings and insights were included in the tabulated summaries. In line with Phase 4 , the team juxtaposed the themes and categories by grouping them, guided by the commensurate focus of the included articles from which the themes and categories were drawn from. The homogeneity of the themes and categories allowed the adoption of reciprocal translation and latterly the mapping of the various themes/categories in Phase 6. These themes/ categories, which form the basis of what Noblit and Hare call "the line of argument", are presented in the "RESULTS" section. The tabulated summaries are found in Appendix 6.

\section{Stage 5: Analysing Data from Research and Non-research-based Sources}

As the research team iteratively streamlined and organized the data, the expert team was critical in overseeing and guiding this process through numerous discussions. In so doing, the expert team considered that data from grey literature that was not quality-assessed or evidence-based could bias the discussion. As such, the research team thematically analyzed data from grey literature and nonresearch-based pieces such as letters, opinion and perspective pieces, commentaries and editorials extracted from the bibliographic databases. When these themes were compared with those from peer-reviewed data, no differences were identified.

\section{Stage 6: SSR Synthesis}

The Best Evidence Medical Education (BEME) Collaboration guide ${ }^{49}$ and the STORIES (Structured approach to the Reporting In healthcare education of Evidence Synthesis) statement ${ }^{61}$ were adopted to guide the SSR narrative. 


\section{RESULTS}

A total of 10443 titles and abstracts were reviewed and a final 76 full-text articles included. Our thematic and directed content analyses yielded similar themes and categories. Following the Jigsaw Perspective and Funnelling stages, we categorized these themes as follows: characteristics of PIF in relation to professionalism (in medicine), role of socialization in PIF, enablers and barriers to PIF, and medical school approaches to supporting PIF.

\section{PIF characteristics in relation to professionalism}

PIF and professionalism are mutually reinforcing, each influencing the other. PIF is a necessary foundation to professionalism ${ }^{62}$ while also contingent upon it. Professionalism in medicine is a process of adopting a shared belief system that focuses on improving the health of patients ${ }^{63,64}$ by attaining technical and cognitive clinical competencies ${ }^{65-69}$, meeting high ethical and moral standards ${ }^{64,67-71}$, and displaying behaviours consistent with professional principles and values $9,64,69,72-74$. To exemplify the profession's expectations as a lifelong ideal, students must be able to reconcile their personal and professional identities.

Critical to the formation of professional identity, on the other hand, is a commitment to the profession ${ }^{62,72,75-77}$. When this commitment deepens through an ongoing process of adapting, internalizing and assimilating professional traits into intrinsic characteristics (virtue-based professionalism) and observable actions (behaviour-based professionalism) $2,5,6,68,69,76,78-80$, a new integrated identity takes shape $2,5,6,68,69,76,78-80$. Factors that influence professional behaviour include mentorship and role-modeling ${ }^{81,82}$, prevailing codes of conduct ${ }^{67}$ and social and cultural concepts of the "good physician" ${ }^{82}$. Manifesting such professional values and behaviours can further foster professional identity $2,5,64,75-$ $77,80,83$, through which medical students identify as a member of the profession $67,84,85$ and aim to embody its roles and responsibilities 2,6,8,9,62,63,65,66,68,69,72-75,80,83,85-96.

Affirming the importance of professional attitudes, ethical conduct, reflective practice and supportive relationships, PIF thus captures the nuanced process by which a medical student personally and professionally transforms into a doctor ${ }^{2,97}$.

\section{Socialization in PIF}

Socialization is the process of becoming a part of the medical community ${ }^{7,72,98}$ and developing a sense of professional identity through shared knowledge and skills ${ }^{72,98}$. This process is individualized, non-linear and heavily influenced by formal ${ }^{5,98,99}$, informal and hidden curricula ${ }^{4,72,98}$. As students move from early peripheral involvement ${ }^{8,72,100}$ to assuming a more central role in the community of practice with increasing seniority ${ }^{69,72,98,101}$, intrinsic characteristics, values, beliefs, behaviours and biases are re-examined ${ }^{62,63,69,80,93-96}$, refined ${ }^{9,73,100}$, re-aligned and integrated. Socialization is facilitated by formal ceremonies and seminal experiences such as White Coat Ceremony and cadaveric dissections ${ }^{62,69}$, and promoted when experiencing patient care $2,6,62,69,76,83,102$, managing clinical responsibilities ${ }^{8,72,100}$, working long hours 5 and reflecting upon experiences and clinical identities $5,69,71,83,96,99$. This evolving process, which continues along the continuum of medical education, sees individuals advance progressively from "doing" toward a way of "being" 69.

\section{PIF influencing factors}

A series of influencing factors promote or hinder professional identity formation as enablers or barriers that are intrinsic or extrinsic to the student. These are presented in Table 1 through the person-centric lens of RToP and its Individual, Relational and Societal Rings. Limited data on the Innate Ring prevented further evaluation of the impact of PIF on this aspect.

Intrinsic factors refer to the medical student's attitudes, values, beliefs, moral and philosophical leanings and decision-making processes. Extrinsic factors relate to the clinical environment. Many factors influence how medical students reconcile their experiences $7,9,67,72,103$ and reflections within the Individual Ring of ideals, values, beliefs, and personal and professional self-concepts ${ }^{4,91}$, while interactions 73,81,100,103-106 impact Relational and Societal Rings. These rings are further affected by how experiences and reflections take shape in medical school. In the absence of effective, appropriate or adequate support ${ }^{7,72,98}$, enabling factors such as reflection ${ }^{2,71,72,76,89,91,107}$ or socialization ${ }^{69,72,98,101}$ may become barriers that impede the merging of students' personal and professional identities.

\section{Medical School strategies to support PIF}

Approaches that medical schools are taking to support PIF are presented in Table 2. The all-encompassing nature of these efforts signals an absence of clear or consistent approach across schools. What these reported strategies share is a foundation of pedagogical practices that view learning as a social construct, value role models, provide guided reflective practice, and institute longitudinal, inclusive and tailored forms of mentorship $71,76,80$ within supportive learning environments ${ }^{7,9,67,72,103}$ in which espoused and enacted values align. The formal ${ }^{5,98,99}$ and hidden curricula ${ }^{4,72,98}$ heavily influence students' socialization into the medical community ${ }^{7,72,98}$. As poignantly stated by Hodges et al. ${ }^{108}$, even if "a student can be prepared for excellent communication, collaboration, empathy, and patient-centered attitudes through years of formal training, just a few minutes in a work environment that does not model these behaviors will rapidly lead to their extinction in the student's behaviors". ${ }^{108}$

\section{DISCUSSION}

Findings from our review support the notion that PIF involves iterative construction, deconstruction and inculcation of 
Table 1 Enablers and barriers to professional identity formation in medical school viewed through the RToP lens

\begin{tabular}{|c|c|c|c|}
\hline & Intrinsic enablers & Extrinsic enablers & Barriers \\
\hline & Medical student is able to: & Learning environment enables: & Student perceives or experiences: \\
\hline Societal Ring & $\begin{array}{l}\text { - Acknowledge societal expectations } \\
\text { pertaining to professional role, } \\
\text { responsibilities and codes of } \\
\text { conduct } 10,67,72,73,101,105,118,119 \\
\text { - Identify with medical professionals } \\
\text { and wider healthcare community } \\
2,5,6,54,63-65,78,81,120,121 \\
\text { - Exhibit professional behaviour in } \\
\text { daily practice } 74 \\
\text { - Fulfil entrusted responsibilities as a } \\
\text { member of the healthcare team } \\
2,65,70,73,77,103,122 \\
\text { - Build confidence with application of } \\
\text { communication, counselling and } \\
\text { clinical reasoning skills to contribute to } \\
\text { the care of their patients } 73,103,122\end{array}$ & $\begin{array}{l}\text { - Symbolic socialization events such } \\
\text { as White Coat Ceremony or Honor } \\
\text { Code } 62,67,69,118,123 \\
\text { - Direct and repeat opportunities to } \\
\text { interact with patients } 62,67,69,118,123 \\
\text { - Meaningful professional relationships } \\
\text { with multidisciplinary healthcare teams } \\
5,8-10,54,64,65,71,72,74,82,84,89,93,96,97,99,102-104 \text {, } \\
\text { 107,124 } \\
\text { - Clarity of role within team and wider } \\
\text { healthcare system } \\
\text { - Formal curriculum to foster holistic, } \\
\text { longitudinal knowledge acquisition and } \\
\text { clinical education } \\
2,5-7,10,54,62-65,67,69,71-74,76-79, \\
81-84,88,89,91,93-97,100-105,109,110,118-132 \\
\text { - Art and humanities opportunities to foster } \\
\text { creativity, acknowledge emotions and } \\
\text { explore identities } 89,92,119 \\
\text { - Hidden curriculum to align intended and } \\
\text { enacted professional values and behaviours } \\
2,4-10,54,62,64,65,68-72,75,78-80, \\
82-84,88-90,93-95,97,99,103-105,119,121,122,132,133\end{array}$ & $\begin{array}{l}\text { - Disconnect between theoretical } \\
\text { knowledge and application in clinical } \\
\text { practice } 97,98 \\
\text { - Heavy academic demands and } \\
\text { competing responsibilities } 82,106,107,130 \\
\text { - Tensions between personal values } \\
\text { and broader professional identity } \\
\text { instigated by challenging encounters } \\
4,7,65,81 \\
\text { - Negative portrayal of profession by } \\
\text { mainstream media or glamorization of } \\
\text { traits such as cynicism } 68,99,124 \\
\text { - Lack of opportunities or expectations } \\
\text { to assume patient care responsibilities } \\
88,98,101,103 \\
\text { - Difficulty navigating or fitting into } \\
\text { new clinical environments }\end{array}$ \\
\hline Relational Ring & $\begin{array}{l}\text { - Develop professional relationships } \\
\text { with patients, peers and team } \\
\text { members } 72,84,88,97,124,132\end{array}$ & $\begin{array}{l}\text { - Supportive clinical interactions between } \\
\text { patients and students; students and doctors } \\
\text { - Collaborative relationships among peers } \\
74,81,84,101,128,129,131 \\
\text { - Open and supportive discussions with } \\
\text { faculty and peers } 65,73,74,81,129,131 \\
\text { - Access to appropriate mentorship, advising } \\
\text { and role modeling } 72,128 \\
\text { - Guided reflective opportunities with } \\
\text { feedback } 7,10\end{array}$ & $\begin{array}{l}\text { - Mismatch between personality and } \\
\text { values with those of team members or } \\
\text { patients } 72,82,91,100 \\
\text { - Challenging relationships with team } \\
\text { member, patients or peers } 88 \\
\text { - Hierarchical structures in clinical } \\
\text { environment deterring students from } \\
\text { seeking help or speaking up } 7,9,72,101 \\
\text { - No mentors or role models } 72,128\end{array}$ \\
\hline Individual Ring & $\begin{array}{l}\text { - Show desire and sustain motivation } \\
\text { to gain competence and engage in } \\
\text { life-long learning } 88,101 \\
\text { - Attend to emotions and engage in } \\
\text { critical thinking and } \\
\text { reflection } \\
2,4-6,9,10,54,62,64,66-68,71-74,78-81,84 \text {, } \\
86,91,92,94,99,102,105,107,109,110,121,123,125-\text { - } \\
128,134\end{array}$ & $\begin{array}{l}\text { - Access to support systems including } \\
\text { mentors and role models } 5,69,71,80,93,121 \\
\text { - Exposure to challenging clinical } \\
\text { experiences such as death and suffering } 118 \\
\text { - Outlets for emotional and/or creative } \\
\text { expression } 89,92,119\end{array}$ & $\begin{array}{l}\text { - Tension between existing personal } \\
\text { identity and aspiring professional } \\
\text { identity } 7,65,81 \\
\text { - Uncertainty or lack of confidence in } \\
\text { clinical interactions that cast doubt on } \\
\text { ability to fulfil professional tasks } \\
54,64,80,96,99 \\
\text { - Unrealistic or conflicting } \\
\text { expectations 4,7,65,73,81,89 } \\
\text { - Absence of role models } \\
72,128\end{array}$ \\
\hline
\end{tabular}

professional beliefs, value systems and codes of conduct into a pre-existent concept of personhood. Students refine, reject or internalize new values, practices and behaviours while reexamining pre-existing ones. Such cycles of shaping and reshaping personal and professional identities are influenced by many factors including role models, reflections or responsibilities along the medical education continuum, as conceptualized in Figure 3. By viewing PIF through the RToP lens in this systematic scoping review, we identified a multitude of intrinsic and extrinsic factors that promote or impede individual, relational and societal aspects of a medical student's personhood (Table 1). Importantly, if inadequately or inappropriately supported, enabling factors can become barriers to PIF.

As different aspects of a medical student's personhood evolve in medical school, personal and professional beliefs or values may pose as competing forces. Making sense of complex or ambiguous experiences necessitates a critical ability to question assumptions, attend to emotions and explore different perspectives. Deconstructing the self to pursue congruence among multiple existing identities can be disorienting or disconcerting. Left to their own devices, learners may consider open questioning of assumptions socioculturally inappropriate, or find existing power relations unapproachable. They may arrive at incomplete or incorrect conclusions, experience feelings of inadequacy and impostorship, and withdraw from learning activities to avoid being "found out". The complex process of PIF, as an outcome of medical education, is thus not a solitary or self-directed exercise for students to steer in a vacuum. While successful formation of a professional identity has been linked to career success, a mismatch between a person's internal bearings and professional roles and expectations can create anxiety, frustration, and feelings of inadequacy, sometimes leading the individual to leave the profession ${ }^{109,110}$. 
Table 2 Strategies adopted by Medical Schools to support Professional Identity Formation

\begin{tabular}{lll}
\hline \hline & Strategies adopted by medical schools to support PIF & References \\
\hline $\begin{array}{l}\text { Formal ethics and } \\
\text { professionalism }\end{array}$ & Prioritizing principles of professionalism and professional & $2,6,7,10,54,62,64,67,71,73,74,77,78,80,82,84,88,89,91,93-$ \\
$97,100,101,103-105,109,110,119-132,135$
\end{tabular}

professionalism

instruction

Informal and hidden curriculum

Learning environment

Symbolic socialization

Medical humanities

Reflective practice

Stories and storytelling

Mentorship

Role models

Non-medical influences identity formation consistently through curricular goals

(professional roles, codes of practice, patient-centred care, ethics instruction, cultural sensitivity, clinical reasoning, communication skills, interprofessional education) using relevant instructional methods (e.g. didactic classroom learning, online modules, seminars, lectures, tutorials, group projects, small-group discussions, reflective writing, experiential learning, community care), and including a system for timely and appropriate feedback to help students improve in clinical capabilities

Performing formative and summative assessment of professionalism as opportunities for learning, remediation, and in extreme cases, exclusion if a student severely violates codes of conduct

Acknowledging the significant influence of informal interactions with the medical community, role models and patients during profound life moments such as birth, death or suffering on student learning, values, attitudes, behaviours, specialty choice or perceived suitability for medicine Establishing guidelines to ensure safe and open learning environments in which learner confidentiality is maintained, student behaviours such as competing, comparing, interrupting, prescribing and speaking on behalf of another are mitigated; open and non-judgmental discourse supported; and professional behaviour reinforced as an indicator of future conduct

Conducting contextually appropriate symbolic events such as White Coat Ceremony to foster socialization into the profession

Formally incorporating humanities with modules as outlets for creative release and emotional expression through art and stories that support empathy, compassion, tolerance of uncertainty and critical thinking on issues such as ethics and social justice

Enabling deliberate and guided reflection strategies using discourse and small-group discussions with feedback throughout students' medical education to help them uncover assumptions, explore different perspectives, make sense of challenging encounters, grapple with ethical quandaries, manage difficult emotions or conflict, and construct and deconstruct values and identity through comparisons between lived experiences and prevailing narratives of meaning, all aiming to inform future actions and decisions

Offering opportunities for students to recollect and verbalize stories of patient encounters, make meaning as events are recalled and structured (i.e. "storied"), shape a personal framework of caring, and develop a coherent physician ideal through critical reflection

Providing formal, purposeful, accessible, inclusive and longitudinal mentorship, as one-on-one or group mentoring models, with qualified faculty aware of power dynamics of interactions with students and equipped with appropriate mentoring skills including feedback to guide students reflect on experiences, navigate professional life, and assimilate knowledge into clinical practice

Cultivating positive role models (e.g. doctors, near-peers, residents, faculty, inter-professional team members) who support students' psychological well-being, encourage reflection, support learning, and demonstrate decision-making and professional values and attitudes in clinical and non-clinical contexts

Acknowledging the role of family, prior experiences, medical dramas and societal perceptions on students' personal values vs. professional expectations, and supporting students to mitigate dissonance and enhance alignment between professional development (e.g. professional attitudes, roles and behaviours) and internal bearings and identity (e.g. personal values), which if left unaddressed could lead to anxiety, frustration, and feelings of inadequacy
$5,8-10,54,62,69,75,82-84,88-90,93,95,97,103-105,119,121,122,132,133$

$81,84,91,107,123,132$

$62,67,69,118,123$

$89,92,119$

$2,5,6,9,10,54,62,64,66-68,71,73,74,78$

$81,84,86,91,92,94,99,102,105,107,109,110,121,123,125-128,134$

$90,103,105,110,129$

$3,54,66,80,81,88,93,99,102,104,124,129$

$5,8-10,54,64,71,72,74,80,82,84,89,93,96,97,99,102-104,107,118,124$

72,84
To support PIF, medical schools are offering attention and action in multiple domains as encapsulated in Table 2. Any measure implemented by a medical school will by its nature affect students at societal and relational levels, with 


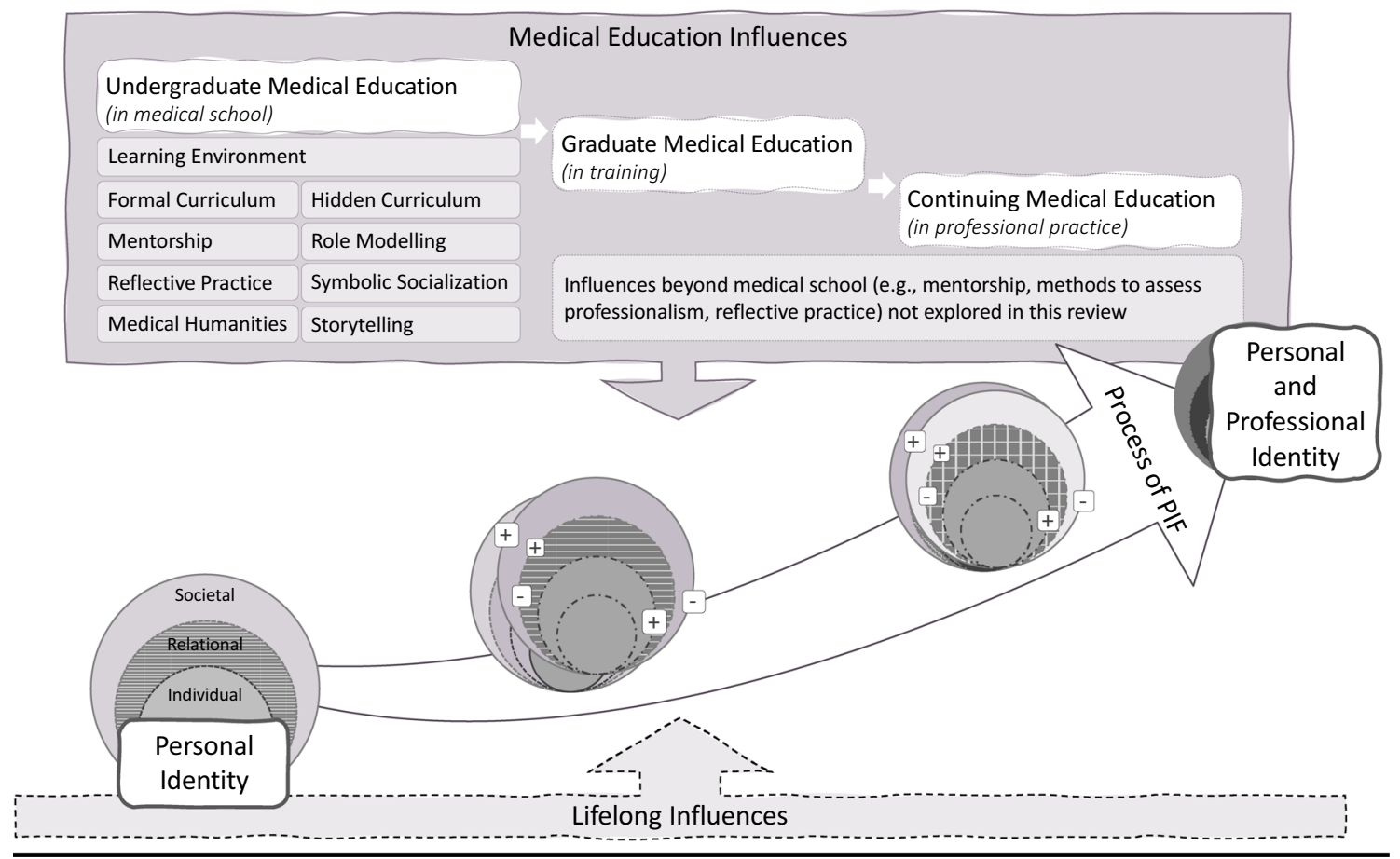

Figure 3 Integration of personal and professional identity entails a longitudinal, developmental process influenced by enabling $(+)$ and disabling $(-)$ factors that impact one's personhood along the continuum of medical education

downstream effects that reshape individual and even intrinsic aspects of their personhood. Caring for the dying, for example, can influence medical students' conceptions of life, death and religion. However, our review does not shed light on how everyday personal interactions ${ }^{111}$, gender roles, online experiences ${ }^{72,84}$, religious beliefs or existential philosophies shape students' understanding of the profession and professional roles. Donning on a white coat does not sever a student's personal proclivities, motivations and priorities. To do so would ignore the humanism and multifarious sources of influence upon a student's life. There is a dearth of data on the influence of a student's personal roles — as a child, spouse, parent, friend, member of the larger community — on their professional conduct and identity. Further literature on this angle could illuminate the extent to which experiences in one's personal sphere may influence professional values, attitudes and behaviours.

Professionalism and PIF are bidirectionally related but distinct entities. At a time when unethical behaviour, burnout and suicide in clinical practice are on the rise $31,112-115$, it is all the more essential for medical schools to explicitly promote their expectations and ideals of the profession through formal instruction, reflective opportunities, mentoring and feedback, aided by processes such as individualized developmental portfolios ${ }^{116,117}$, along with a multi-faceted program of assessment. The challenge with the latter remains a lack of consistency and clarity on the constituent constructs within professionalism and PIF through established theoretical frameworks.

\section{LIMITATIONS}

We acknowledge several limitations to this study. Guiding the analysis through the RToP lens is novel, and organization of factors within the four rings reflected the researchers' own preconceptions. To reach consensus with minimal overlaps between and across categories required iterative communication to align our understanding of PIF influences and their relation to the rings. Further, despite a comprehensive search from snowballing of references and oversight from content experts, it is possible to have missed relevant literature. The included articles, by nature of scoping reviews, were of varying categories and caliber, and the majority represented Western perspectives, questioning generalizability within different contexts.

\section{CONCLUSION}

PIF is a complex, non-linear and fluid process through which medical students navigate competing influences between their professional roles and personal lives, and iteratively construct and deconstruct evolving views of the self. In the absence of a unifying theoretical framework, we explored this process through the lens of personhood and encapsulated key factors that promote or hinder students' identity development on individual, relational or societal levels. Also captured were the all-encompassing strategies that medical schools implement to support their students' socialization into the profession. Deliberate efforts to foster inspiring mentored relationships and individualized guided reflections in supportive learning environments can foster the agency for students to 
harmonize their personal and professional identities over time, with the ultimate aim of improving practice on individual, institutional and societal levels.

Supplementary Information The online version contains supplementary material available at https://doi.org/10.1007/s11606-02107024-9.

Acknowledgements: The authors would like to dedicate this paper to the late Dr. S Radha Krishna whose advice and ideas were integral to the success of this study. The authors would also like to thank the reviewers whose comments greatly enhanced this paper.

Corresponding Author: Lalit Kumar Radha Krishna, MBChB, FRCP, FAMS, MA (Medical Education), MA (Medical Ethics), PhD (Medical Ethics); Palliative Care Institute Liverpool, Academic Palliative \& End of Life Care Centre, University of Liverpool, United Kingdom, Cancer Research Centre, University of Liverpool, Liverpool, UK (e-mail: lalit. radha-krishna@liverpool.ac.uk).

Author Contribution SS, YNT, AEHH, YHT, YTO, CWSC, ASIL, AMCC, MC and LKRK conceived of the study and led the design, data collection, analysis and drafting of the manuscript.

SG, CSK, WYL, RSMW, HZBG, SL, JRMT, RBQL, NPXC, NHAK and LHET participated in study design and conducted data collection. All authors read and approved the final manuscript.

Data Availability All data generated or analysed during this review are included in this published article (and its appendices)

\section{Declarations:}

\section{Ethics Approval and Consent to Participate: NA}

\section{Consent for Publication: NA}

Conflict of Interest: SS, YNT, AEHH, YHT, SG, CSK, WYL, RSMW, HZBG, SL, JRMT, RBQL, YTO, NPXC, CWSC, NHAK, ASIL, LHET, $A M C C, M C, L K R K$ have no competing interests and no funding was received for this review.

Open Access This article is licensed under a Creative Commons Attribution 4.0 International License, which permits use, sharing, adaptation, distribution and reproduction in any medium or format, as long as you give appropriate credit to the original author(s) and the source, provide a link to the Creative Commons licence, and indicate if changes were made. The images or other third party material in this article are included in the article's Creative Commons licence, unless indicated otherwise in a credit line to the material. If material is not included in the article's Creative Commons licence and your intended use is not permitted by statutory regulation or exceeds the permitted use, you will need to obtain permission directly from the copyright holder. To view a copy of this licence, visit http://creativecommons. org/licenses/by/4.0/.

\section{REFERENCES}

1. Matsui T, Sato M, Kato Y, Nishigori H. Professional identity formation of female doctors in Japan-gap between the married and unmarried. BMC Med Educ. 2019;19(1):55.

2. Holden M, Buck E, Clark M, Szauter K, Trumble J. Professional Identity Formation in Medical Education: The Convergence of Multiple Domains. HEC Forum. 2012;24(4):245-255.

3. Frost HD, Regehr G. "I AM a doctor": Negotiating the discourses of standardization and diversity in professional identity construction. Acad Med. 2013;88(10):1570-1577.

4. Monrouxe LV, Sweeney $\mathbf{K}$. Between two worlds: Medical students narrating identity tensions. In: First do no self-harm: Understanding and promoting physician stress resilience. New York: Oxford University Press; 2013:44-66
5. Goldie $\mathbf{J}$. The formation of professional identity in medical students: Considerations for educators. Med Teach. 2012;34(9):e641-e648.

6. Holden MD, Buck E, Luk J, et al. Professional Identity Formation: Creating a Longitudinal Framework Through TIME (Transformation in Medical Education). Acad Med. 2015;90(6):761-767.

7. Soo J, Brett-MacLean P, Cave M-T, Oswald A. At the precipice: A prospective exploration of medical students' expectations of the preclerkship to clerkship transition. Adv Health Sci Educ Theory Pract. 2016;21(1):141-162.

8. Schrewe B, Bates J, Pratt D, Ruitenberg CW, McKellin WH. The Big $\mathrm{D}(\mathrm{eal})$ : Professional identity through discursive constructions of "patient'. Med Educ. 2017;51(6):656-668.

9. Barr J, Bull R, Rooney $\mathbf{K}$. Developing a patient focussed professional identity: An exploratory investigation of medical students' encounters with patient partnership in learning. Adv Health Sci Educ Theory Pract. 2015;20(2):325-338.

10. Wald HS, White J, Reis SP, Esquibel AY, Anthony D. Grappling with complexity: Medical students' reflective writings about challenging patient encounters as a window into professional identity formation. Med Teach. 2019;41(2):152-160.

11. Moss JM, Gibson DM, Dollarhide CT. Professional identity development: A grounded theory of transformational tasks of counselors. $J$ Couns Psychol. 2014;92(1):3-12.

12. Buron B. Levels of personhood: A model for dementia care. Geriatr Nurs 2008;29(5):324-332.

13. Dennett DC. Brainstorms: Philosophical Essays on Mind and Psychology. 1978. In: MIT Press, Cambridge, MA; 1981.

14. Locke J. An essay concerning principles of human understanding (1836). Hackett Publishing Company, Inc.; 1996.

15. Kant I. Groundwork of the Metaphysics of Morals (1785). In: Cambridge University Press; 1998.

16. Cranford RE, Smith DR. Consciousness: the most critical mora (constitutional) standard for human personhood. AJLM. 1987;13:233.

17. Jowett B. The Republic of Plato. London; New York: Macmillan; 1888.

18. Singer P. Rethinking Life and Death. Oxford University Press; 1994.

19. Fletcher JF. Humanhood: Essays in biomedical ethics. Buffalo, New York: Prometheus Books; 1979.

20. Taylor C. Sources of the self: The making of the modern identity. Harvard University Press; 1989.

21. Higgs J, Jones MA, Loftus S, Christensen N. Clinical Reasoning in the Health Professions. 3rd Edition. J Chiropr Educ. 2008;22(2):161-162.

22. Avorn J. The Psychology of Clinical Decision Making - Implications for Medication Use. N Engl J Med. 2018;378(8):689-691.

23. Ramondetta L, Brown A, Richardson G, et al. Religious and spiritual beliefs of gynecologic oncologists may influence medical decision making. Int J Gynecol Cancer. 2011;21(3):573-581.

24. Krishna LKR, Alsuwaigh R. Understanding the Fluid Nature of Personhood-the Ring Theory of Personhood. Bioethics. 2015;29(3):171181

25. Alsuwaigh R, Krishna LKR. The compensatory nature of personhood. Asian Bioeth Rev. 2014;6(4):332-342.

26. Krishna LKR, Kwek SY. The changing face of personhood at the end of life: The ring theory of personhood. Palliat Support Care. 2015; 13(4): 1123 .

27. Krishna LKR, Alsuwaigh R, Miti PT, Wei SS, Ling KH, Manoharan D. The influence of the family in conceptions of personhood in the palliative care setting in Singapore and its influence upon decision making. Am J Hosp Palliat Med. 2014;31(6):645-654.

28. Levac D, Colquhoun H, O'Brien KK. Scoping studies: advancing the methodology. Implement Sci. 2010;5:69.

29. Arksey H, O'Malley L. Scoping studies: towards a methodological framework. Int J Soc Res Methodol. 2005;8(1):19-32.

30. Munn Z, Peters MDJ, Stern C, Tufanaru C, McArthur A, Aromataris E. Systematic review or scoping review? Guidance for authors when choosing between a systematic or scoping review approach BMC Med Res Method. 2018;18(143).

31. Kow CS, Teo YH, Teo YN, et al. A systematic scoping review of ethical issues in mentoring in medical schools. BMC Med Educ. 2020;20(1): 110

32. Krishna LKR, Tan LHE, Ong YT, et al. Enhancing Mentoring in Palliative Care: An Evidence Based Mentoring Framework. J Med Educ Curric Dev. 2020;7:2382120520957649.

33. Ngiam LXL, Ong YT, Ng JX, et al. Impact of Caring for Terminally Ill Children on Physicians: A Systematic Scoping Review. Am J Hosp Palliat Care. 2021;38(4):396-418. 
34. Moher D, Shamseer L, Clarke M, et al. Preferred reporting items for systematic review and meta-analysis protocols (PRISMA-P) 2015 statement. Syst Rev. 2015;4(1):1.

35. Shamseer L, Moher D, Clarke M, et al. Preferred reporting items for systematic review and meta-analysis protocols (PRISMA-P) 2015: elaboration and explanation. BMJ. 2015;350:g7647.

36. Peters M, Godfrey C, McInerney P, Soares C, Khalil H, Parker D. The Joanna Briggs Institute Reviewers' Manual 2015: Methodology for JBI Scoping Reviews. In: Adelaide, SA Australia: The Joanna Briggs Institute; 2015: http://joannabriggs.org/assets/docs/sumari/Reviewers-Manual_Methodology-for-JBI-Scoping-Reviews_2015_v1.pdf. Accessed 29 Apr 2019.

37. Peters MD, Godfrey CM, Khalil H, McInerney P, Parker D, Soares CB. Guidance for conducting systematic scoping reviews. Int $J$ Evid Based Healthc. 2015;13(3):141-146.

38. Sandelowski M, Barroso J. Handbook for synthesizing qualitative research. New York: Springer Publishing Company; 2006.

39. Reed DA, Beckman TJ, Wright SM, Levine RB, Kern DE, Cook DA. Predictive validity evidence for medical education research study quality instrument scores: quality of submissions to JGIM's Medical Education Special Issue. J Gen Intern Med. 2008;23(7):903-907.

40. Tong A, Sainsbury P, Craig J. Consolidated criteria for reporting qualitative research (COREQ): a 32-item checklist for interviews and focus groups. Int $J$ Qual Health Care. 2007;19(6):349-357.

41. Mertz M. How to tackle the conundrum of quality appraisal in systematic reviews of normative literature/information? Analysing the problems of three possible strategies (translation of a German paper). BMC Med Ethics. 2019;20(1):81.

42. Majid U, Vanstone M. Appraising Qualitative Research for Evidence Syntheses: A Compendium of Quality Appraisal Tools. . Qual Healt Res. 2018;28(13):2115-2131.

43. Ng YX, Koh ZYK, Yap HW, et al. Assessing mentoring: A scoping review of mentoring assessment tools in internal medicine between 1990 and 2019. PLoS One. 2020;15(5):e0232511.

44. Chua WJ, Cheong CWS, Lee FQH, et al. Structuring Mentoring in Medicine and Surgery. A Systematic Scoping Review of Mentoring Programs Between 2000 and 2019. J Contin Educ Health Prof. 2020;40(3): 158-168.

45. Braun V, Clarke V. Using thematic analysis in psychology. Qual Res Psychol. 2006;3(2):77-101.

46. Hsieh H-F, Shannon SE. Three approaches to qualitative content analysis. Qual Health Res. 2005;15(9):1277-1288.

47. Soemantri D, Herrera C, Riquelme A. Measuring the educational environment in health professions studies: a systematic review. Med Teach. 2010;32(12):947-952.

48. Riquelme A, Herrera C, Aranis C, Oporto J, Padilla O. Psychometric analyses and internal consistency of the PHEEM questionnaire to measure the clinical learning environment in the clerkship of a Medical School in Chile. Med Teach. 2009;31(6):e221-e225.

49. Haig A, Dozier M. BEME Guide no 3: systematic searching for evidence in medical education-Part 1: Sources of information. Med Teach. 2003;25(4):352-363.

50. Gordon M, Gibbs T. STORIES statement: publication standards for healthcare education evidence synthesis. BMC medicine. 2014;12(1): 143.

51. Boyatzis RE. Transforming qualitative information: Thematic analysis and code development. US: Sage Publications; 1998.

52. Sawatsky AP, Parekh N, Muula AS, Mbata I, Bui T. Cultural implications of mentoring in sub-Saharan Africa: a qualitative study. Med Educ. 2016;50(6):657-669.

53. Elo S, Kyngäs H. The Qualitative Content Analysis Process. J Adv Nurs. 2008;62(1): 107-115.

54. Cruess RL, Cruess SR, Boudreau J, Snell L, Steinert Y. A schematic representation of the professional identity formation and socialization of medical students and residents: A guide for medical educators. Acad Med. 2015;90(6):718-725.

55. Moss PA, Haertel EH. Engaging methodological pluralism. In: Gitomer D, Bell C, eds. Handbook of Research on Teaching. Washington, DC: AERA; 2016:127-247.

56. Wong G, Greenhalgh T, Westhorp G, Buckingham J, Pawson R. RAMESES publication standards: meta-narrative reviews. BMC Med. 2013;11(1):20.

57. Popay J, Roberts H, Sowden A, et al. Guidance on the Conduct of Narrative Synthesis in Systematic Reviews: A Product from the ESRC Methods Programme Version 1. Lancaster University; 2006.
58. France EF, Uny I, Ring $\mathbf{N}$, et al. A methodological systematic review of meta-ethnography conduct to articulate the complex analytical phases. BMC Med Res Methodol. 2019;19(1):35.

59. Noblit GW, Hare RD. Meta-ethnography: synthesizing qualitative studies. Vol 11. California: Sage Publications; 1988.

60. France EF, Wells M, Lang H, Williams B. Why, when and how to update a meta-ethnography qualitative synthesis. Syst Rev. 2016;5:44.

61. Frei E, Stamm M, Buddeberg-Fischer B. Mentoring programs for medical students - A review of the PubMed literature 2000-2008. BMC Med Educ. 2010;10:32.

62. Cruess RL, Cruess SR, Steinert Y. Amending Miller's pyramid to include professional identity formation. Acad Med. 2016;91(2):180-185.

63. Hafferty FW, Michalec B, Martimianakis MA, Tilburt JC. Alternative Framings, Countervailing Visions: Locating the "P" in Professional Identity Formation. Acad Med. 2016;91(2):171-174.

64. Olive KE, Abercrombie CL. Developing a PSShysician's Professional Identity Through Medical Education. Am J Med Sci. 2017;353(2):101108.

65. Rabow MW, Wrubel J, Remen RN. Authentic community as an educational strategy for advancing professionalism: A national evaluation of the Healer's Art course. J Gen Intern Med. 2007;22(10):14221428

66. Kalen S, Ponzer S, Seeberger A, Kiessling A, Silen C. Longitudinal mentorship to support the development of medical students' future professional role: a qualitative study. BMC Med Educ. 2015; 15:97.

67. Byszewski A, Gill JS, Lochnan H. Socialization to professionalism in medical schools: a Canadian experience. BMC Med Educ. 2015;15:204.

68. Iserson KV. Talking About Professionalism Through the Lens of Professional Identity. AEM Educ Train. 2019;3(1):105-112.

69. Cruess RL, Cruess SR, Boudreau JD, Snell L, Steinert Y. Reframing Medical Education to Support Professional Identity Formation. Acad Med. 2014;89(11):1446-1451.

70. Boudreau JD, Cruess SR, Cruess RL. Physicianship: Educating for professionalism in the post-Flexnarian era. Perspect Biol Med. 2011;54(1):89-105.

71. Cruess SR, Cruess RL. Teaching professionalism - Why, What and How. Facts Views Vis Obgyn. 2012;4(4):259-265.

72. Wilson I, Cowin LS, Johnson M, Young H. Professional identity in medical students: Pedagogical challenges to medical education. Teach Learn Med. 2013;25(4):369-373.

73. Hatem DS, Halpin T. Becoming Doctors: Examining Student Narratives to Understand the Process of Professional Identity Formation Within a Learning Community. J Med Educ Curric Dev. 2019;6:2382120519834546.

74. Findyartini A, Sudarsono NC. Remediating lapses in professionalism among undergraduate pre-clinical medical students in an Asian Institution: a multimodal approach. BMC Med Educ. 2018;18(1):88.

75. Boudreau JD, Fuks A. The Humanities in Medical Education: Ways of Knowing, Doing and Being. J Med Humanit. 2015;36(4):321-336.

76. Bynum WEI, Artino ARJ. Who Am I, and Who Do I Strive to Be? Applying a Theory of Self-Conscious Emotions to Medical Education. Acad Med. 2018;93(6):874-880.

77. Bogetz AL, Bogetz JF. An Evolving Identity: How Chronic Care Is Transforming What it Means to Be a Physician. Acad Psychiatry. 2015;39(6):664-668.

78. Sklar DP. How do I figure out what I want to do if I don't know who I am supposed to be? Acad Med. 2015;90(6):695-696.

79. Slotnick HB. How doctors learn: Education and learning across the medical-school-to-practice trajectory. Acad Med. 2001;76:1013-1026.

80. Rabow M, Remen R, Parmelee D, Inui T. Professional Formation: Extending Medicine's Lineage of Service Into the Next Century. Acad Med. 2010;85:310-317.

81. Boudreau JD, Macdonald ME, Steinert Y. Affirming professional identities through an apprenticeship: insights from a four-year longitudinal case study. Acad Med. 2014;89(7):1038-1045.

82. Azmand S, Ebrahimi S, Iman M, Asemani O. Learning professionalism through hidden curriculum: Iranian medical students' perspective. $J$ Med Ethics Hist Med. 2018;11:10.

83. ten Cate O, Gruppen LD, Kogan JR, Lingard LA, Teunissen PW. Time-Variable Training in Medicine: Theoretical Considerations. Acad Med. 2018;93(3S):S6-S11

84. Wong A, Trollope-Kumar K. Reflections: An inquiry into medical students' professional identity formation. Med Educ. 2014;48(5):489501 . 
85. Barone MA, Vercio C, Jirasevijinda T. Supporting the Development of Professional Identity in the Millennial Learner. Pediatrics. 2019;143(3):e20183988.

86. Stephens MB, Bader KS, Myers KR, Walker MS, Varpio L. Examining Professional Identity Formation Through the Ancient Art of Mask Making. J Gen Intern Med. 2019;34(7):1113-1115.

87. Miller E, Balmer D, Hermann N, Graham G, Charon R. Sounding narrative medicine: studying students' professional identity development at Columbia University College of Physicians and Surgeons. Acad Med. 2014;89(2):335-342.

88. Gaufberg E, Bor D, Dinardo P, et al. In Pursuit of Educational Integrity: Professional Identity Formation in the Harvard Medical School Cambridge Integrated Clerkship. Perspect Biol Med. 2017;60(2):258274

89. Volpe RL, Hopkins M, Van Scoy LJ, Wolpaw DR, Thompson BM. Does Pre-clerkship Medical Humanities Curriculum Support Professional Identity Formation? Early Insights from a Qualitative Study. Med Sci Educ. 2019;29(2):515-521

90. Figley C, Huggard P, Rees C. First Do No Self Harm. Oxford University Press; 2013.

91. Peterson WJ, House JB, Sozener CB, Santen SA. Understanding the Struggles to Be a Medical Provider: View Through Medical Student Essays. J Emerg Med. 2018;54(1):102-108.

92. Shapiro J, Youm $\mathbf{J}$, Heare $\mathbf{M}$, et al. Medical Students' Efforts to Integrate and/or Reclaim Authentic Identity: Insights from a MaskMaking Exercise. J Med Humanit. 2018;39(4):483-501.

93. Fergus KB, Teale B, Sivapragasam M, Mesina O, Stergiopoulos E. Medical students are not blank slates: Positionality and curriculum interact to develop professional identity. Perspect Med Educ. 2018;7(1):5-7.

94. Aagaard EM, Moscoso L. Practical implications of compassionate offramps for medical students. Acad Med. 2019;94(5):619-622.

95. Sharpless J, Baldwin N, Cook R, et al. The becoming: students' reflections on the process of professional identity formation in medical education. Acad Med. 2015;90(6):713-717

96. Cruess SR, Cruess RL, Steinert Y. Supporting the development of a professional identity: General principles. Med Teach. 2019;41(6):641649

97. Kavas MV, Demiroren M, Kosan AM, Karahan ST, Yalim NY. Turkish students' perceptions of professionalism at the beginning and at the end of medical education: a cross-sectional qualitative study. Med Educ Online. 2015;20:26614

98. Schei E, Johnsrud RE, Mildestvedt T, Pedersen R, Hjorleifsson S Trustingly bewildered. How first-year medical students make sense of their learning experience in a traditional, preclinical curriculum. Med Educ Online. 2018;23(1):1500344.

99. Chuang AW, Nuthalapaty FS, Casey PM, et al. To the point: reviews in medical education-taking control of the hidden curriculum. Am $J$ Obstet Gynecol. 2010;203(4):316.e311-316.e316.

100. Steinauer JE, O'Sullivan P, Preskill F, Ten Cate O, Teherani A. What Makes "Difficult Patients" Difficult for Medical Students? Acad Med. 2018;93(9): 1359-1366.

101. Smith SE, Tallentire VR, Cameron HS, Wood SM. The effects of contributing to patient care on medical students' workplace learning. Med Educ. 2013;47(12):1184-1196.

102. Byars LA, Stephens MB, Durning SJ, Denton GD. A Curricular Addition Using Art to Enhance Reflection on Professional Values. Mi Med. 2015;180(suppl_4):88-91.

103. Konkin J, Suddards C. Creating stories to live by: caring and professional identity formation in a longitudinal integrated clerkship. Adv Health Sci Educ Theory Pract. 2012;17(4):585-596.

104. De Grasset J, Audetat MC, Bajwa N, et al. Medical students' professional identity development from being actors in an objective structured teaching exercise. Med Teach. 2018;40(11):1151-1158.

105. Jarvis-Selinger S, MacNeil KA, Costello GRL, Lee K, Holmes CL Understanding Professional Identity Formation in Early Clerkship: A Novel Framework. Acad Med. 2019;94(10):1574-1580.

106. Ahmad A, Bahri Yusoff MS, Zahiruddin Wan Mohammad WM, Mat Nor MZ. Nurturing professional identity through a community based education program: medical students experience. J Taibah Univ Med Sci 2018;13(2):113-122

107. Wang XM, Swinton M, You JJ. Medical students' experiences with goals of care discussions and their impact on professional identity formation. Med Educ. 2019;53(12):1230-1242.

108. Hodges BD, Kuper A. Theory and practice in the design and conduct of graduate medical education. Acad Med. 2012;87(1):25-33.
109. Reis SP, Wald HS. Contemplating medicine during the Third Reich: Scaffolding professional identity formation for medical students. Acad Med. 2015;90(6):770-773.

110. Easton G. How medical teachers use narratives in lectures: a qualitative study. BMC Med Educ. 2016;16:3.

111. Finn G, Garner J, Sawdon M. 'You're judged all the time!'Students' views on professionalism: a multicentre study. Med Educ. 2010;44(8):814-825.

112. Dzau VJ, Kirch DG, Nasca TJ. To Care Is Human - Collectively Confronting the Clinician-Burnout Crisis. NEJM. 2018;378:312-314.

113. Wright AA, M.P.H., Katz IT. Beyond Burnout - Redesigning Care to Restore Meaning and Sanity for Physicians. $N$ Engl $J$ Med. 2018;378:309-311.

114. Lee FGH, Chua WJ, Cheong CWS, et al. A Systematic Scoping Review of Ethical Issues in Mentoring in Surgery. $J$ Med Educ Curric Dev 2019;6:2382120519888915.

115. Cheong CWS, Chia EWY, Tay KT, et al. A systematic scoping review of ethical issues in mentoring in internal medicine, family medicine and academic medicine. Adv Health Sci Educ Theory Pract. 2020;25(2):415439.

116. Van Tartwijk J, Driessen EW. Portfolios for assessment and learning: AMEE Guide no. 45. Medical Teacher. 2009;31(9):790-801.

117. Colbert CY, Ownby AR, Butler PM. A Review of Portfolio Use in Residency Programs and Considerations before Implementation. Teaching and Learning in Medicine. 2008;20(4):340-345.

118. Kay D, Berry A, Coles NA. What experiences in medical school trigger professional identity development? Teach Learn Med. 2019;31(1):17-25.

119. Beck J, Chretien $\mathbf{K}$, Kind $\mathbf{T}$. Professional Identity Development Through Service Learning: A Qualitative Study of First-Year Medical Students Volunteering at a Medical Specialty Camp. Clin Pediatr (Phila). 2015;54(13): 1276-1282.

120. Helmich E, Dornan T. Do you really want to be a doctor? The highs and lows of identity development. Med Educ. 2012;46(2): 132.

121. Hargreaves K. Reflection in medical education. JUTLP. 2016;13(2):6.

122. van der Zwet J, Zwietering PJ, Teunissen PW, van der Vleuten $\mathbf{C P}$, Scherpbier AJ. Workplace learning from a socio-cultural perspective: creating developmental space during the general practice clerkship. Adv Health Sci Educ Theory Pract. 2011;16(3):359-373.

123. Shiozawa T, Glauben M, Banzhaf M, et al. An Insight into Professiona Identity Formation: Qualitative Analyses of Two Reflection Interventions During the Dissection Course. Anat Sci Educ. 2019.

124. Schweller M, Ribeiro DL, Celeri EV, de Carvalho-Filho MA. Nurturing virtues of the medical profession: does it enhance medical students' empathy? Int J Med Educ. 2017;8:262-267.

125. Ten Cate $\mathbf{O}$. What is a 21 st-century doctor? Rethinking the significance of the medical degree. Acad Med. 2014:89(7):966-969.

126. Till A, McKimm J, Swanwick T. Twelve tips for integrating leadership development into undergraduate medical education. Med Teach 2018;40(12):1214-1220.

127. Lin L. Fostering students' professional identity using critical incident technique. Med Educ. 2012;46(11):1132-1133.

128. Seymour P, Watt M, MacKenzie M, Gallea M. Professional Competencies ToolKit: Using Flash Cards to Teach Reflective Practice to Medical Students in Clinical Clerkship. MedEdPORTAL. 2018;14:10750.

129. Cave MT, Clandinin DJ. Revisiting the journal club. Med Teach. 2007;29(4):365-370.

130. Madill A, Latchford G. Identity change and the human dissection experience over the first year of medical training. Soc Sci Med. 2005;60(7): 1637-1647.

131. Swick HM, Simpson DE, Van Susteren TJ. Fostering the professional development of medical students. Teach Learn Med. 1995;7(1):55-60.

132. Schei E, Knoop HS, Gismervik MN, Mylopoulos M, Boudreau JD Stretching the Comfort Zone: Using Early Clinical Contact to Influence Professional Identity Formation in Medical Students. J Med Educ Curric Dev. 2019;6:2382120519843875.

133. Noguera A, Robledano R, Garralda E. Palliative care teaching shapes medical undergraduate students' professional development: a scoping review. Curr Opin Support Palliat Care. 2018;12(4):495-503.

134. Roper L, Foster K, Garlan K, Jorm C. The challenge of authenticity for medical students. Clin Teach. 2016;13(2):130-133.

135. Bynum IV WE, Artino Jr ARJAM. Who am I, and who do I strive to be? Applying a theory of self-conscious emotions to medical education. 2018:93(6):874-880

Publisher's Note: Springer Nature remains neutral with regard to jurisdictional claims in published maps and institutional affiliations. 